A Research Report for

Westinghouse Hanford Company

\title{
Cesium Capsule Thermal Analysis
}

\author{
L. L. Eyler \\ R. E. Dodge
}

December 1989

Prepared for the U.S. Department of Energy under Contract DE-AC06-76RLO 1830

Pacific Northwest Laboratory

Operated for the U.S. Department of Energy

by Battelle Memorial Institute 


\title{
DISCLAIMER
}

This program was prepared as an account of work sponsored by an agency of the United States Government. Neither the United States Government nor any agency thereof, nor Battelle Memorial institute, nor any or their employees, makes any waranty, expreased or implied, or assumes any lespal liability or respondibltity for the accuracy, completeness, or usefulness of any information, apparatus, product, or process disclosed, or represents that its use would not infringe privatehy owned rights. Reference herein to any specific commercial product, process, or service by trade name, trademark, manufacturer, or otherwise, does not necessarily constitute or imply its endorsement, recommendation, or favoring by the United States Government of any agency thereof, or Battelle Memorial Institute. The views and opinions of authors expressed herein do not necessarily state or reflect those of the United States Government or any agency thereof.

\author{
PACIFIC NORTHWEST LABORATORY \\ operated by \\ BATTELLE MEMORIAL INSTITUTE \\ for the \\ UNITED STATES DEPARTMENT OF ENERGY \\ under Contract DE-AC06-76RLO 1830
}

Printed in the United States of America

Available to DOE and DOE contractors from the

Office of Scientific and Technical Information, P.O. Box 62, Oak Ridge, TN 37831; prices available from (615) 576-8401. FTS 626-0401.

Available to the public from the National Technical Information Service, U.S. Department of Commerce, 5285 Port Royal Rd., Springfieid, VA 22161.

NTIS Price Codes, Microfiche A01

\begin{tabular}{|c|c|}
\hline \multicolumn{2}{|c|}{ Printed Copy } \\
\hline Pages & $\begin{array}{l}\text { Price } \\
\text { Codes }\end{array}$ \\
\hline $001-025$ & $\mathrm{~A} 02$ \\
\hline $026-050$ & $\mathrm{~A} 03$ \\
\hline 051-075 & $\mathrm{A} 04$ \\
\hline $076-100$ & A05 \\
\hline $101-125$ & $A 06$ \\
\hline $126-150$ & A07 \\
\hline $151-175$ & $\mathrm{AOB}$ \\
\hline $176-200$ & $A 09$ \\
\hline $201-225$ & A10 \\
\hline $226-250$ & A17 \\
\hline $251-275$ & A12 \\
\hline $276-300$ & A13 \\
\hline
\end{tabular}


A Research Report for
Westinghouse Hanford Company

CESIUM CAPSULE THERMAL ANALYSIS

L. L. Eyler

R. E. Dodge

December 1989

Prepared for

the U.S. Department of Energy

under Contract DE-ACD6-76RLO 1830

Pacific Northwest Laboratory

Richland, Washington 99352 


\section{SUMMARY}

Double-walled stainless steel capsules, produced by the Hanford Waste Encapsulation and Storage Facility (WESF), were designed to facilitate storage of radioactive cesium chloride (CsC1). The capsules were later determined to be a useful resource for irradiation facilities (IFs), and are currently being used at several comercial IFs. A capsule at one of these facilities recently failed, resulting in a release of the $\operatorname{Csc} 1$.

A thermal analysis of a WESF capsule was performed by Pacific Northwest Laboratory (PNL) at the request of Westinghouse Hanford Company. In this analysis, parametric calculations demonstrated the impact that various parameters have on the temperature distribution within a capsule in a commercial irradiation facility. Specifically, the effect of varying the gas gap conductivity, the exterior heat sink temperatures, the exterior heat transfer distribution, the stainless steel emissivity, and the gamma heating rate were addressed. In addition, a calculation was performed to estimate the highest temperatures likely to have been encountered in one of these capsules.

A "best estimate of worst case" calculation for the parameter range considered in this analysis predicted a maximum centerline $\mathrm{CsCl}$ temperature of $468^{\circ} \mathrm{C}$ and a maximum surface temperature of $289^{\circ} \mathrm{C}$. 



\section{ACKNOWLEDGMENTS}

The authors wish to thank Walter Knecht of Westinghouse Hanford Company, the Technical Manager of this project, for his guidance and for the opportunity to perform this work. 
. 


\section{CONTENTS}

SUMMARY

ACKNOWLEDGMENTS

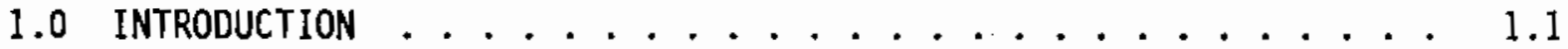

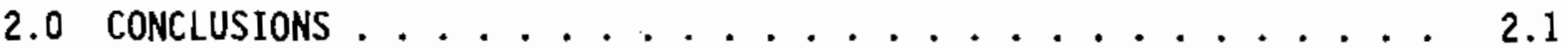

3.0 PROBLEM DESCRIPTION . . . . . . . . . . . . . . . 3.1

4.0 ANALYSIS APPROACH ................... 4.1

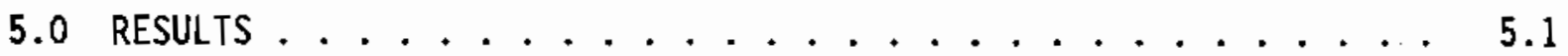

5.1 COMPUTER MODEL ........................ 5.1

5.2 SINGLE CAPSULE CONFIRMATORY COMPARISON . . . . . . 5.4

5.3 EXTERIOR FLOW ANALYSIS ............... 5.4

5.4 CAPSUle MidPlane PARAMETRIC CALCULATIONS . . . . . 5.9

5.4.1 Base Case and CsCl Fill Level Varjation. . . . . 5.10

5.4.2 Effects of Helium in the Capsule Gap . . . . . . 5.11

5.4.3 Radial Temperature Distributions with Heljum in the Capsule Gap ............. 5.12

5.4.4 Effect of External Sink Temperature . . . . . . 5.15

5.4.5 Effect of Thermal Radiation Sink Temperature . . . 5.16

5.4.6 Effect of Gama Heating . . . . . . . . . 5.16

5.5 BEST ESTIMATE OF WORST CASE . . . . . . . . . . 5.22

REFERENCES ......................... R. I

APPENDIX A - MATERIAL PROPERTIES ................. A.1 


\section{FIGURES}

3.1 Drawer Schematic . . . . . . . . . . . . 3.2

3.2 Capsule Configuration and Dimensions .......... 3.3

5.1 Capsule Quarter-Section Mode1 . . . . . . . . . . 5.2

5.2 Quarter-Section Noding Diagram ........... 5.5

5.3 200-Watt Single Capsule Radial Temperature Distribution . . . . 5.6

5.4 Rack Assembly Schematic . . . . . . . . . . . . . . 5.7

5.5 Rack Assembiy Noding Diagram . . . . . . . . . . . 5.8

5.6 Exterior Channel Temperatures . . . . . . . . . . . 5.9

5.7 Radial Temperature Distributions with Air in the Capsule Gap . . 5.11

5.8 Radial Temperature Distributions with Helium in the Capsule Gap . 5.12

5.9 Maximum Temperature Dependence on the Adiabatic Angle . . . . 5.13

5.10 Surface Temperature Dependence on the Adiabatic Angle . . . . . . 5.14

5.11 Surface Temperature Variation ............. 5.14

5.12 Effect of Thermal Radiation Sink Temperature . . . . . . . 5.16

5.13 Effect of Emissivity on Temperature . . . . . . . . . . 5.17

5.14 Radial Temperature Profiles for Distributed Power Calculations. . 5.21

5.15 Radial Temperature Distribution for "Best Estimate of Worst

Case" Calculation ............... 5.22

\section{TABLES}

5.1 Base Case Parameters ............... . . . 5.10

5.2 Radiation View Factors . . . . . . . . . . . . 5.19

5.3 Gamma-Heating Factors . . . . . . . . . . . . 5.20

5.4 Power Deposition for Results in Figure 5.13 . . . . . . 5.21 


\subsection{INTRODUCTION}

Cesium capsules produced by the Hanford Waste Encapsulation and Storage Facility (WESF) are double-walled stainless steel vessels containing cesium137 chloride $(\mathrm{CsCl})$. The capsules were originally designed for long-term storage of the radioactive $\mathrm{CsCl}$, but were Tater determined to be a valuable resource for irradiation facilities (IFs). They have been used at the Sandia Irradiator for Dried Sewage Solids (SIDSS) plant, and are currently being used at several commercial IFs. The commercial IFs assemble an array of the capsules to produce the desired radiation field. Recently a capsule at one of these facilities failed, resulting in a release of the $\mathrm{CsCl}$.

The purpose of this analysis performed by Pacific Northwest Laboratory (PNL), (a) at the request of Westinghouse Hanford Company, is to provide a best estimate of the centerline and surface temperatures of the hottest capsules in the array at the Hanford Site experiencing the failure. This information can then be used to estimate the thermally induced stresses in the capsule.

(a) PNL is operated for the U.S. Oepartment of Energy by Battelle Memorial Institute under Contract DE-AC06-76RL.0 1830. 



\subsection{CONCLUSIONS}

Several parametric calculations were performed, to determine the sensitivity of the calculated temperature profiles to specific model parameters. The findings of this study are:

- A "best estimate of worst case" calculation for the parameter range considered in this analysis predicted a maximum centerline temperature of $468^{\circ} \mathrm{C}$ in the $\mathrm{CsCT}$, and a maximum surface temperature of $289^{\circ} \mathrm{C}$. This calculation was based on a two-thirds-full capsule with a thermal power output of $160 \mathrm{~W}$, air in the capsule gap, sink temperatures of $149^{\circ} \mathrm{C}$, capsules full of $\mathrm{CsCl}$, and stainless steel emissivity of 0.8 . Thermal and gamma heating from neighboring capsules was also included in this calculation.

- The maximum temperature is sensitive to the following parameters:

- gas gap thermal conductivity

- exterior sink temperature

- exterior heat transfer distribution

- stainless steel emissivity

- thermal power deposited by gamma heating.

- Azimuthat variation in temperature is only significant in the exterior stainless steel wall. The maximum azimuthal variation in the outer wall is $18^{\circ} \mathrm{C}$, and is less than $2^{\circ} \mathrm{C}$ in the inner wall. The $\mathrm{CsCl}$ exhibits negligible azimuthal temperature variation.

- Decreasing the stainless steel emissivity can result in significantly higher temperatures. For example, for one set of parameters, decreasing $\epsilon$ from 0.8 to 0.4 leads to an increase in maximum centerline temperature of $60^{\circ} \mathrm{C}$. However, 0.8 was used in most of this analysis because it is a "best estimate" of the actual value.

- Gamma heating from the $\mathrm{CsCl}$ increases maximum wall temperatures slightly (approximately $12^{\circ} \mathrm{C}$ ). 


\subsection{PROBLEM DESCRIPTION}

The geometry analyzed consists of a drawer and rack assembly, with an array of 34 drawers. The drawers are arranged in a five-wide by seven-high array, with no drawer in the top center position. Each drawer contains six cesium capsules oriented vertically and side by side. The capsules are held in place by retaining bars in a wire mesh screen. The rack containing the drawers is a steel framework approximately 5-in. deep, with no back plates. The configuration is shown schematically in Figure 3.1, with approximate dimensions.

The capsule assembly is shown in Figure 3.2. Each capsule is 20.775 in. $(0.5277 \mathrm{~m})$ long, with a cavity length of $18.925 \mathrm{in}$. $(0.4807 \mathrm{~m})$. It is made up of two concentric steel tubes, each with welded end caps. A thin annular region separates the tubes, producing a double-walled vessel for the CSCl. The effect on temperature of the choice of gas in the annular region is investigated in this study.

The total power in each capsule is nominally $240 \mathrm{~W}$. For each capsule, $160 \mathrm{~W}$ is nominally deposited internal to the capsule and $B 0 \mathrm{~W}$ escapes as gamma rays which are deposited elsewhere. Some of the gamma rays will be attenuated causing gamma heating in the capsule walls of the emitting capsule, and some will be deposited in adjacent capsules. As shown in the analysis section of this report, the gamma heating is not significant for capsules more than one diameter away from the emitting capsule. 


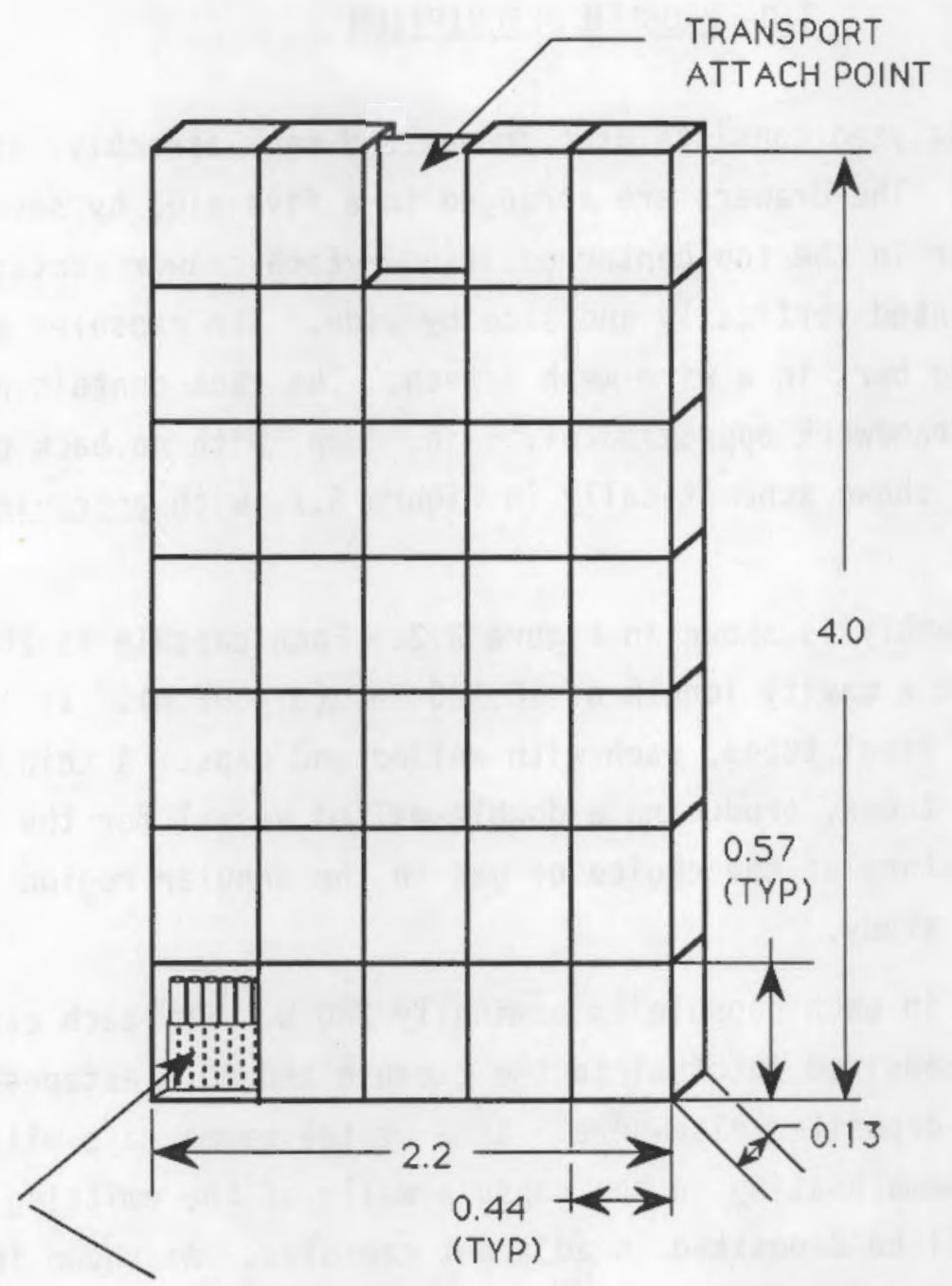

WIRE BASKET

WITH CAPSULES

(TYP 34 PLACES)

NOTES:

1. NOT TO SCALE

2. DIMENSIONS IN METERS

3. ALL DIMENSIONS ARE APPROXIMATE.

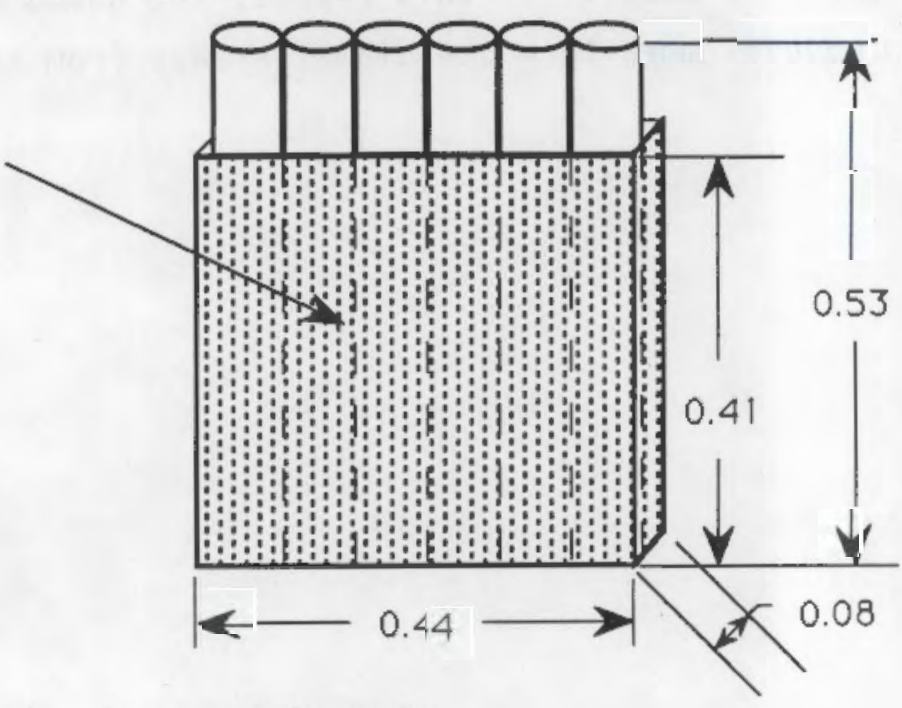

FIGURE 3.1. Drawer Schematic 


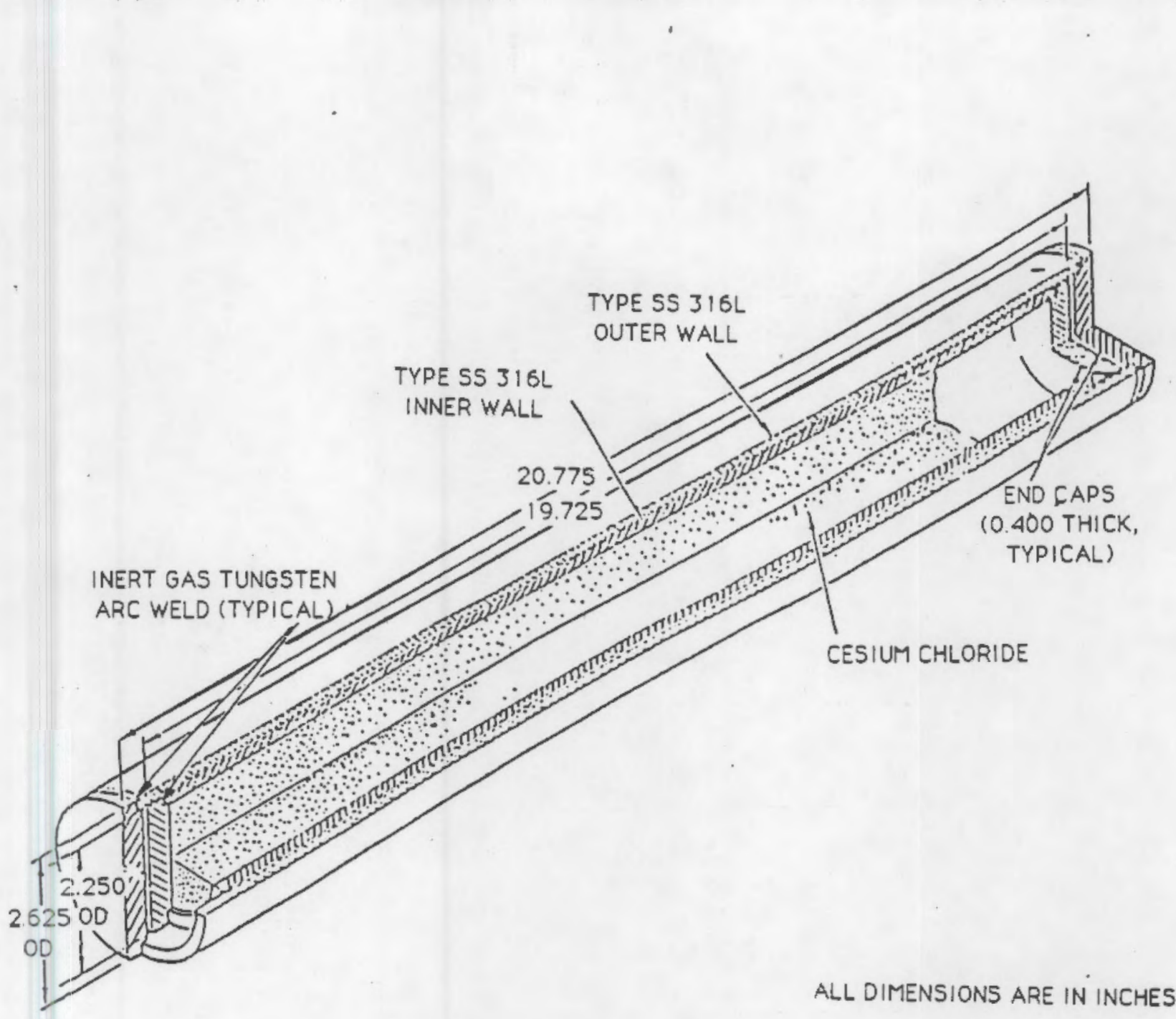

FIGURE 3.2. Capsule Configuration and Dimensions 

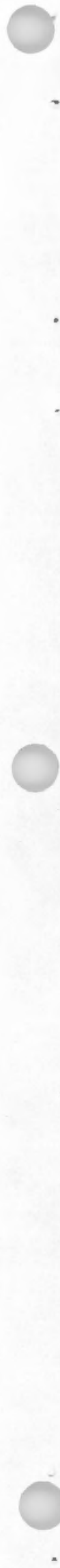


\subsection{ANALYSIS APPROACH}

There were three parts to this analysis. First, a confirmatory calculation of the temperature distribution in the $r-\theta$ plane was performed, and the results were compared with the findings of Knecht (1988) and Tingey et al. (1985). This calculation confirmed the validity of performing a twodimensional calculation in the transverse plane. In the second part of the analysis, a simplified calculation of the external heat transfer in the array of capsules was performed. This calculation provided boundary conditions for the third part of the analysis, wherein a midplane calculation of the hottest capsule provided an estimate of the temperatures experienced by the hottest capsule. These analyses are described in detail in the body of this report.

For the midplane analysis, parametric calculations were performed, to determine the sensitivity of the model to the following parameters:

- gas gap thermal conductivity

- exterior sink temperature

- exterior heat transfer distribution

- stainless steel emissivity

- thermal power deposited by gamma heating. 

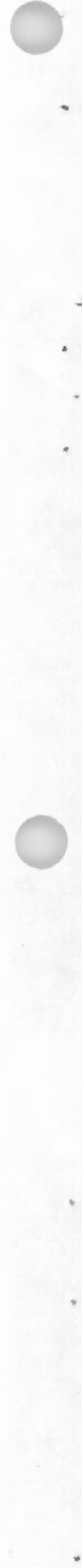


\subsection{RESULTS}

This section describes the computer model and presents results of the single capsule confirmatory calculation, the exterior flow analysis, and capsule midplane parametric calculations analysis.

A curvilinear version of the TEMPEST computer code was used to perform these analyses. TEMPEST is a very powerful, general purpose, thermal hydraulic computer code capable of performing unsteady, three-dimensional, turbulent flowfield calculations on generalized grids. It can handle solid, liquid and gaseous elements, and includes convective, conductive and radiative heat transfer models. The TEMPEST code is documented by Trent and Eyler (1988, 1989).

\subsection{COMPUTER MODEL}

Although the capsules are arranged six abreast in each drawer, to calculate the most severe temperature profiles only a one-quarter section of the central capsule needs to be modeled, as shown in Figure 5.1. This quarter section was discretized in the radial and azimuthal directions. Conduction heat transfer takes place in the $\mathrm{CsCl}$ and the stainless steel walls. In the gap between the walls, radiation heat transfer was considered in parallel with conduction through the gas gap. For conduction, heat transfer is modeled as

$$
q_{c}=h_{c} \Delta T
$$

where $h_{c}$ is an effective conductivity defined as

$$
h_{c}=\frac{k_{\text {gap }}}{\Delta x}
$$

and the gas gap conductivity and thickness are $k_{\text {gap }}$ and $\Delta x$, respectively. 

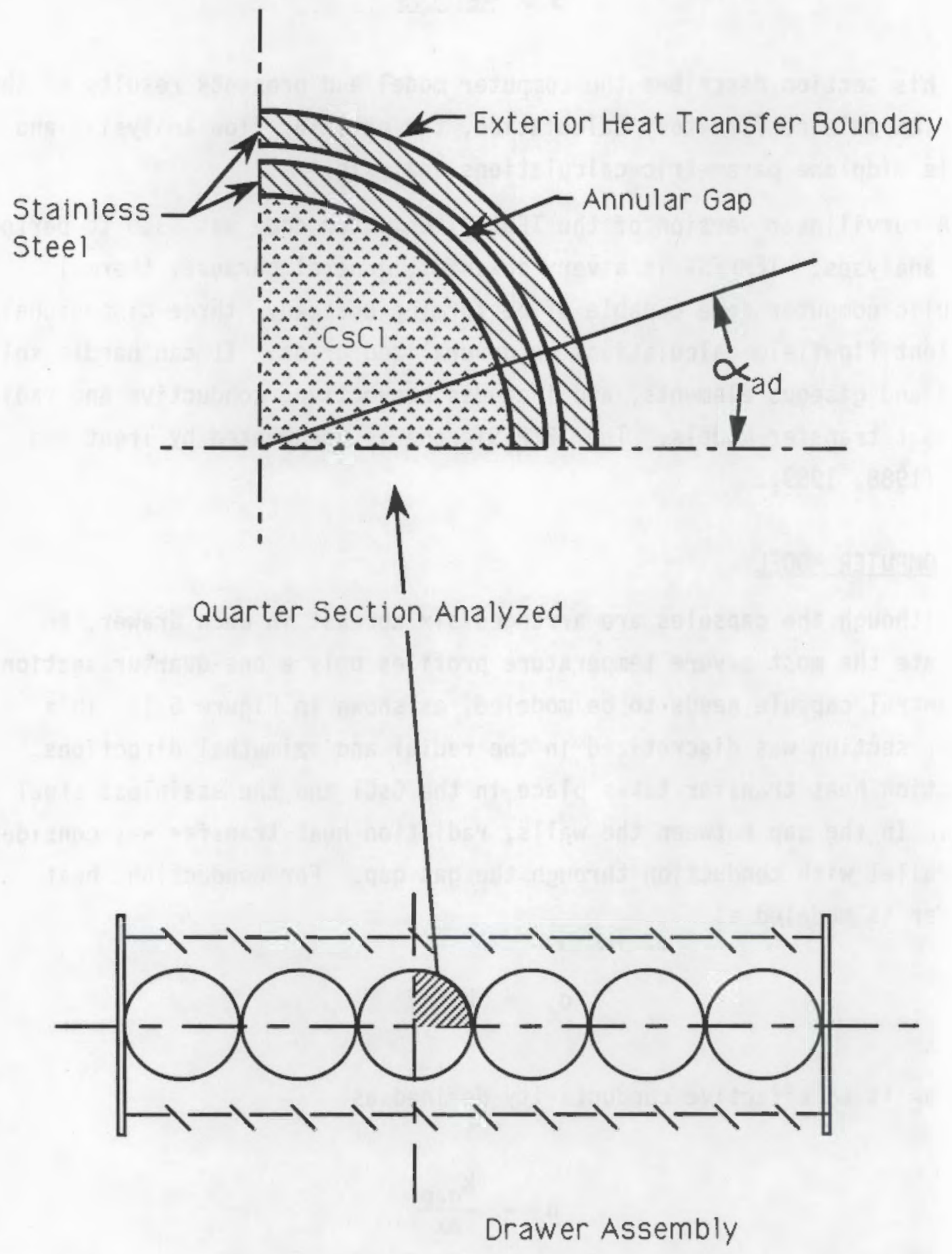

FIGURE 5.1. Capsule Quarter-Section Mode1 
For thermal radiation, the heat transfer is modeled as

$$
q_{R}=h_{R} \Delta T
$$

where $h_{R}$ is a radiation heat transfer coefficient defined as

$$
h_{R}=\frac{\epsilon \sigma\left(T_{i}^{4}-T_{0}^{4}\right)}{\left(T_{i}-T_{0}\right)}
$$

and $\sigma \quad=$ Stefan-Boltzman constant

$\epsilon \quad=$ Thermal Emissivity

$T_{j}, T_{0}=$ Temperatures between which radiation is occurring.

This expression is valid for thin gap heat transfer where the areas of the radiating bodies are similar, and the emissivities are the same. The above expression is also valid when radiating to an infinite environment. It is therefore also used to model radiation from the exterior surface of the capsule.

Convection heat transfer is also considered on the exterior surface. The expression used is (Holman 1963),

$$
h_{c}=1.5 \Delta T^{1 / 3}
$$

where $h_{C}$ is in $W / m^{2}-{ }^{\circ} C$ and $\Delta T$ is in degrees celsius. This was derived from the more general expression of

$$
\mathrm{Nu}=0.13 \mathrm{Ra}^{1 / 3}
$$

for air flow conditions over a large flat plate at $\overline{\mathrm{T}} \sim 100^{\circ} \mathrm{C}$.

The material properties used for $\mathrm{CsCl}$ are given in Appendix $\mathrm{A}$. 


\subsection{SINGLE CAPSULE CONFIRMATORY COMPARISON}

To verify the approach and modeling in the current analysis, a calculation of an isolated capsule is performed. The noding diagram used in the calculation is given in Figure 5.2. The results are compared with the findings from similar calculations as reported by Tingey et al. (1985) and Knecht (1988) in Figure 5.3. All three calculations show very similar results. Very good agreement is obtained with Tingey's results, even though he performed calculations in the $r-z$ plane and this analysis is in the $r-\theta$ midplane. This agreement confirms that a midplane analysis correctly models the hottest-capsule temperature behavior. Additionally, the midplane analysis allows inclusion of the azimuthal variations due to the side-by-side configuration of capsules.

\subsection{EXTERIOR FLOW ANALYSIS}

In order to include the effects of the environment (e.g., neighboring capsules and walls) on the temperature of the cesium capsule, a simple calculation of the full cesium capsule array was performed. The TEMPEST code was used for this calculation also. For this part of the analysis, it was assumed that each capsule was emitting $160 \mathrm{~W}$ of thermal power. Thus, a total power of $16,320 \mathrm{~W}$ would be lost on each side of the rack. The model is shown schematically in Figure 5.4, and the noding scheme is shown in Figure 5.5. For this analysis, a shroud plate at a distance of $4 \mathrm{in}$. from the wire mesh face was included. This configuration should provide a conservative (hot) estimate of the actual temperature external to the capsules.

Figure 5.6 presents the temperature distribution calculated for the air layer between the wire mesh and the capsule surface. Note that at the upper drawer air temperatures become rather warm, reaching a value of nearly $170^{\circ} \mathrm{C}$. The channel average outlet temperature is only $60.3^{\circ} \mathrm{C}$, and the air has an average velocity of $1.69 \mathrm{~m} / \mathrm{sec}$. This indicates that the wire mesh is (or can be) rather restrictive to intermixing between the free stream and the air layer. (The effect of the wire mesh was not exhaustively studied in this work.) 


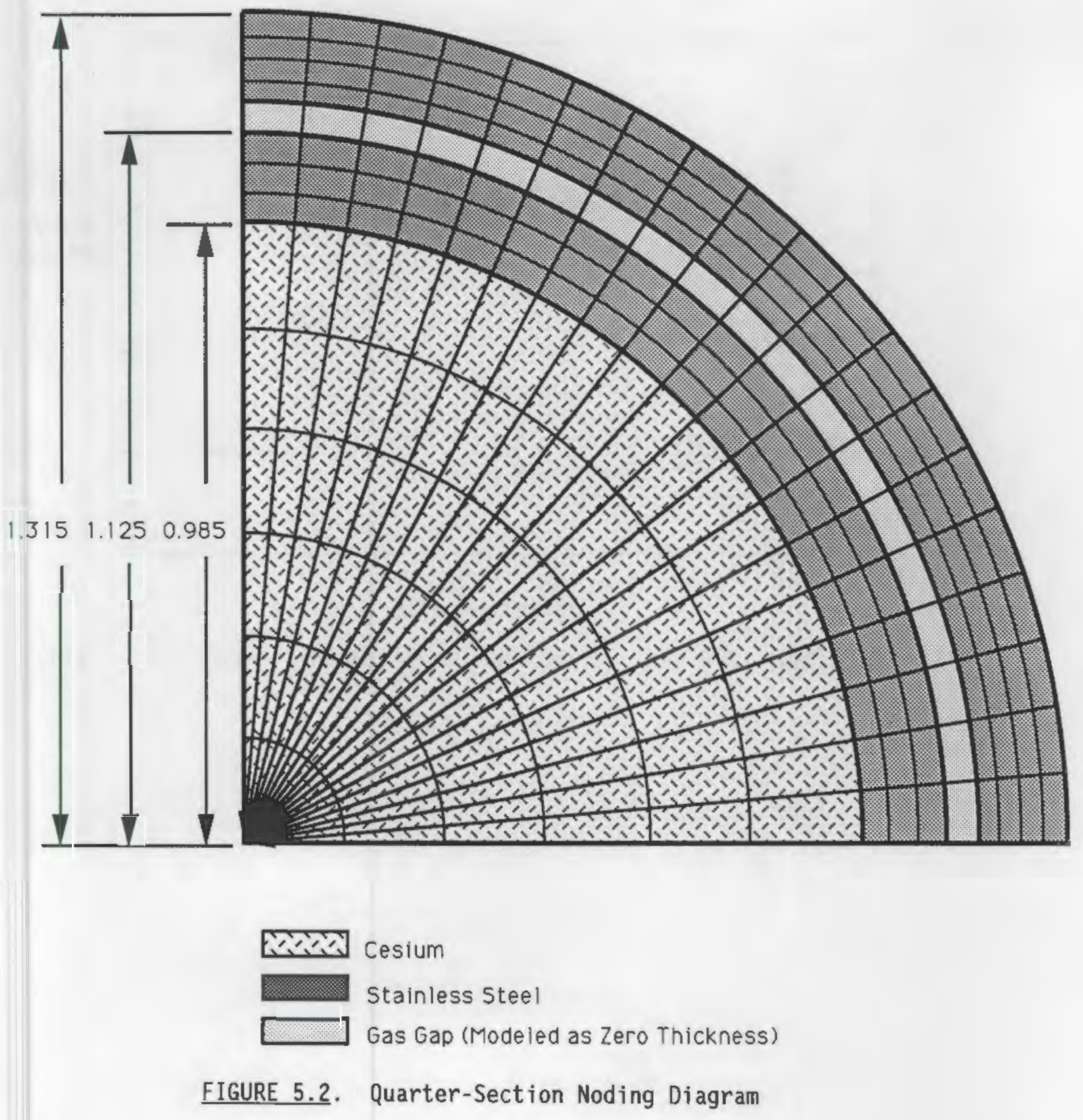




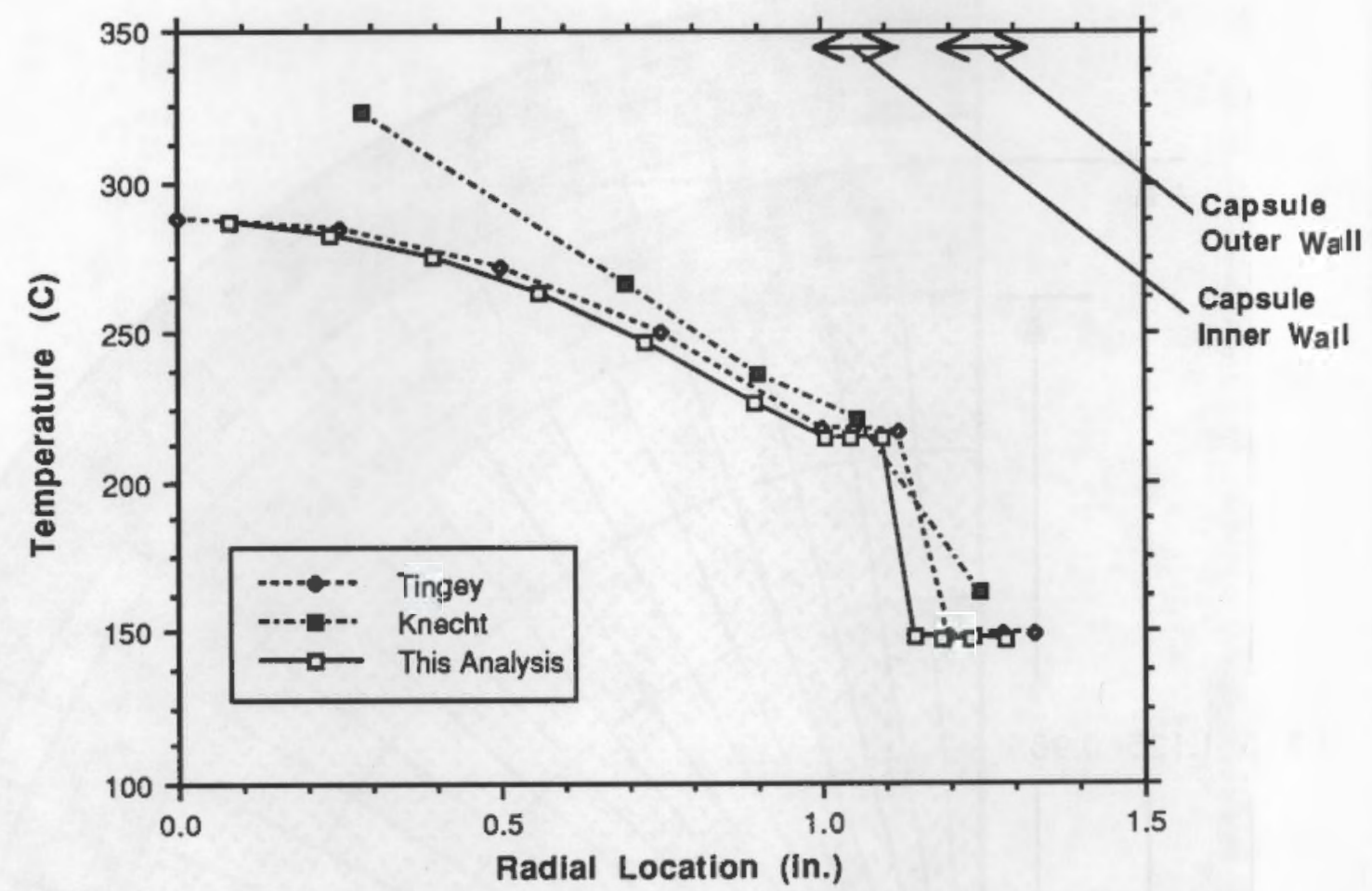

FIGURE 5.3. 200-Watt Single Capsule Radial Temperature Distribution 


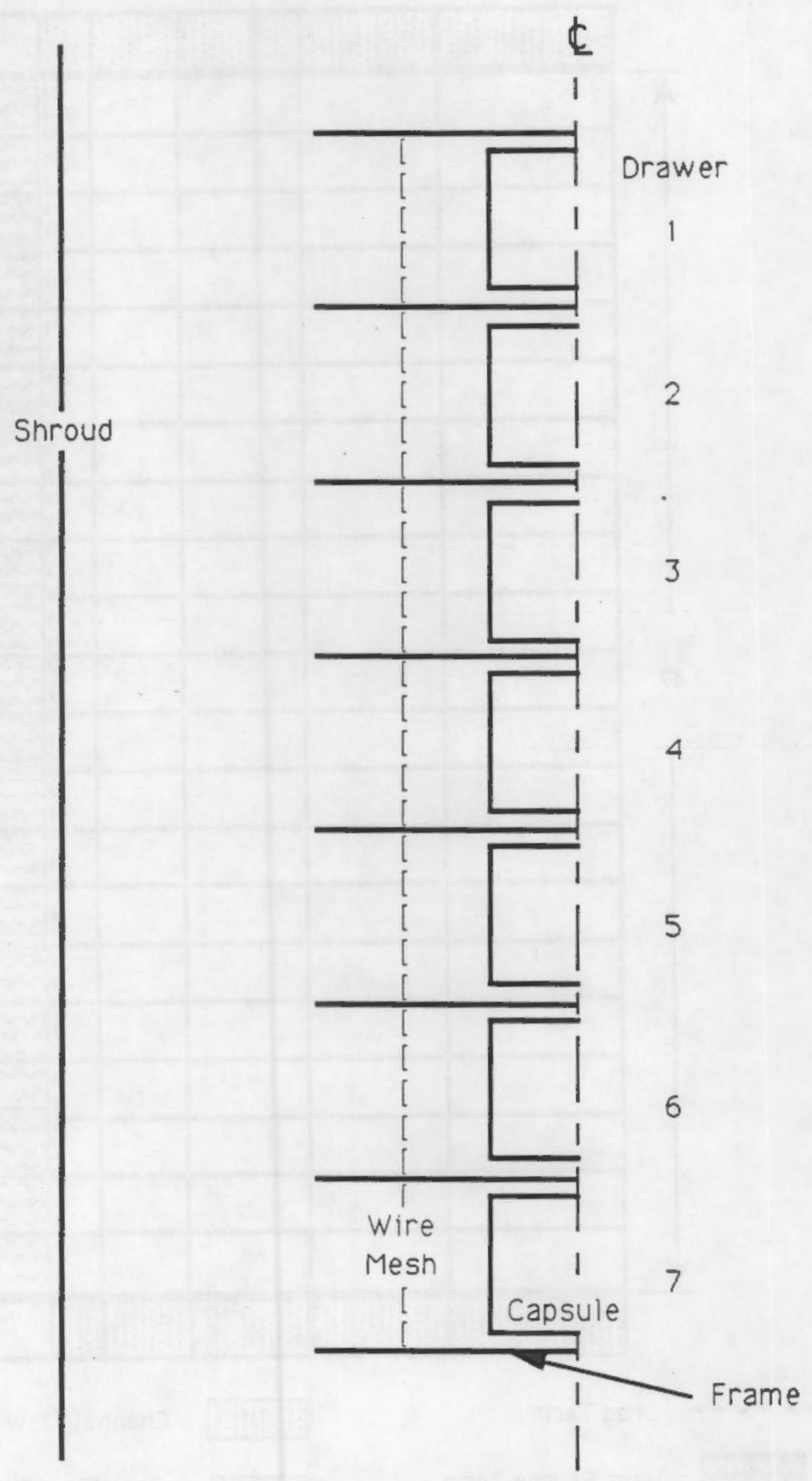

FIGURE 5.4. Rack Assembly Schematic 


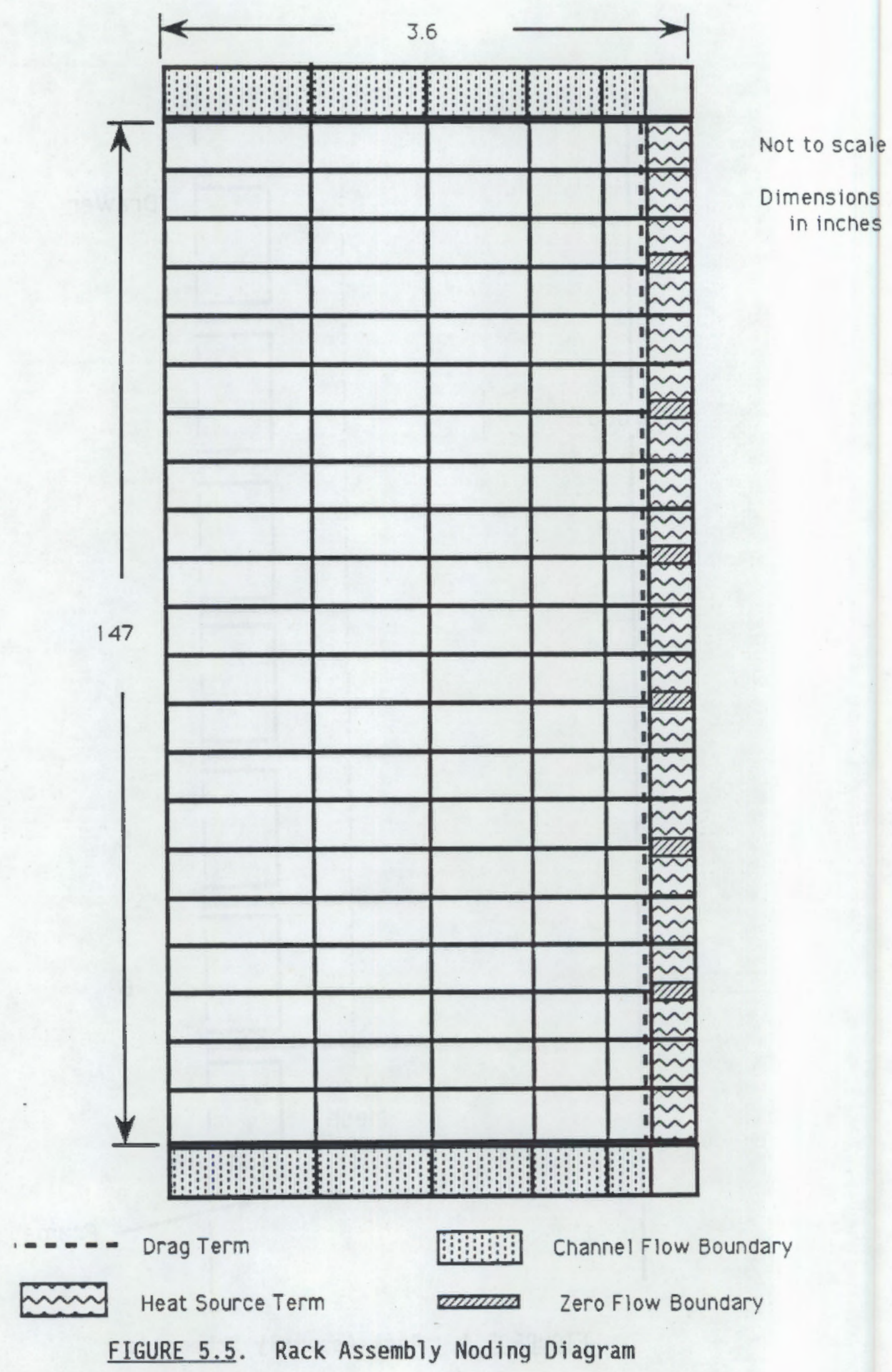




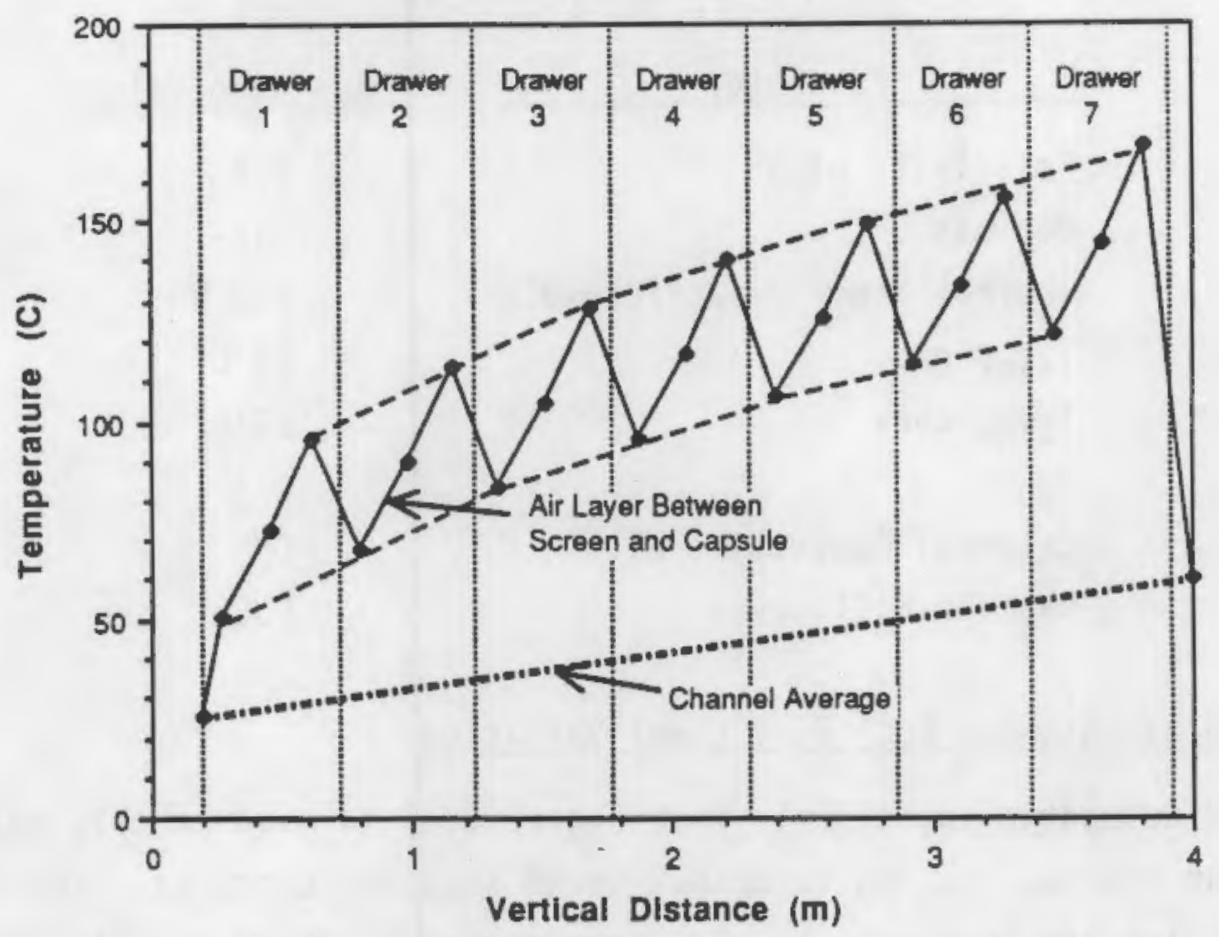

FIGURE 5.6. Exterior Channel Temperatures

The results of this calculation provide a basis for estimating an external convective heat transfer sink temperature. This sink temperature may be quite different than the thermal radiation sink temperature because thermal radiation does not "see" the air temperature, but rather sees a surface temperature of whatever solid objects are in "view."

\subsection{CAPSULE MIDPLANE PARAMETRIC CALCULATIONS}

The parameters that are varied in this analysis are the fill level of the $\mathrm{CsCl}$ in the capsules, the gas in the capsule annular gap, the amount of thermal power absorbed from adjacent capsules, the convection and radiation sink temperatures, and the stainless steel emissivity. In addition, a rough calculation of the magnitude and effects of gamma heating is included. The base case parameters are shown in Table 5.1. 
TABLE 5.1. Base Case Parameters

\begin{tabular}{|c|c|}
\hline Parameter & Base Case Value \\
\hline Emissivity of SS & 0.8 \\
\hline Gap Gas & Air \\
\hline Thermal Power Output/Capsule & $160 \mathrm{~W}$ \\
\hline $\mathrm{T}_{\text {sink }} \mathrm{rad}$ & $25^{\circ} \mathrm{C}$ \\
\hline $\mathrm{T}_{\text {sink }}$ conv & $25^{\circ} \mathrm{C}$ \\
\hline$\alpha_{\text {ad }}$ & $0^{\circ}$ \\
\hline External Convective HT & ON \\
\hline Capsule Fill Level & FULL \\
\hline
\end{tabular}

\subsubsection{Base Case and CSCl Fill Level Variation}

The adiabatic angle, $\alpha_{a d}$, (see Figure 5.1 ) is used in this analysis to model the thermal heating contribution of adjacent capsules. The fact that the capsules are in a side-by-side arrangement leads to an adiabatic condition at $\alpha_{\text {ad }}=0$, the point of contact. Extending this angle to include a larger area of the cylinder provides a convenient method of approximating the effects of neighboring capsules. Analyses, such as those by Sparrow (1961) for arrays of cylindrical rods, indicate that as the ratio of pitch to diameter tends towards 1, e.g., touching, the heat transfer is significantly reduced beyond about $15^{\circ}$ angles. In the present work, this condition was parameterized up to an angle of $45^{\circ}$ over which no heat transfer occurs.

For the base case, setting this angle to zero essentially ignores the direct heating by adjacent capsules. The resulting problem has no theta dependency for temperature.

The radial temperature profile for a capsule in this base case configuration is shown in Figure 5.7. Also shown in this figure are the results for lower-fill levels in the capsule, but at the same total power (i.e., at a higher power density). The radial location of the stainless steel tubing can be identified as the plateaus in these plots. The temperature through the tubing is essentially constant due to the thinness of the tubes and the high thermal conductivity of stainless steel. 


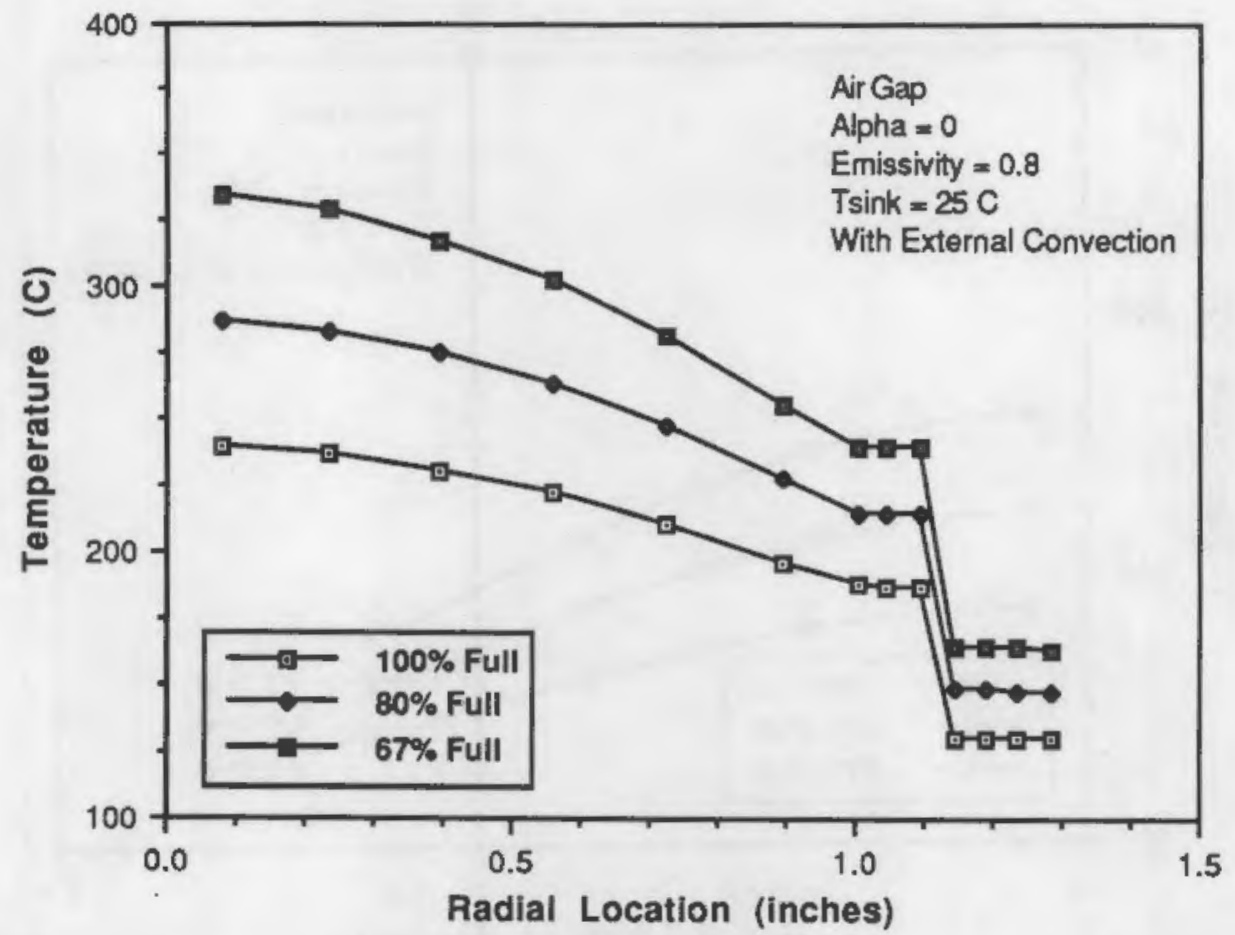

FIGURE 5.7. Radial Temperature Distributions with Air in the Capsule Gap

The peak temperature for the base case is $240^{\circ} \mathrm{C}$ at the centerline, decreasing to $187^{\circ} \mathrm{C}$ at the inner wall of the capsule, and to $130^{\circ} \mathrm{C}$ at the outer wall. If the fill level is decreased to $80 \%$, then these temperatures increase to $287^{\circ} \mathrm{C}$ at the centerline, $215^{\circ} \mathrm{C}$ at the inner wall, and $148^{\circ} \mathrm{C}$ at the outer wall. A further decrease in fill level to $67 \%$ full results in corresponding temperatures of $334^{\circ} \mathrm{C}, 240^{\circ} \mathrm{C}$, and $164^{\circ} \mathrm{C}$.

\subsubsection{Effects of Helium in the Capsule Gap}

Figure 5.8 shows results for the same case, except the annular gap in the capsule is now assumed to be filled with helium instead of air. Helium has a much larger thermal conductivity than air, and thus results in lower temperatures. The peak temperatures are $50^{\circ}$ to $70^{\circ} \mathrm{C}$ cooler than for the previous cases, and the wall temperatures are correspondingly lower.

It is worth noting that within the two-dimensional approximations applied in this analysis, the partially filled cesium capsule analyses could also be interpreted as higher power capsule calculations, subject to the same boundary conditions. Since the analysis in the midplane treats the capsule 


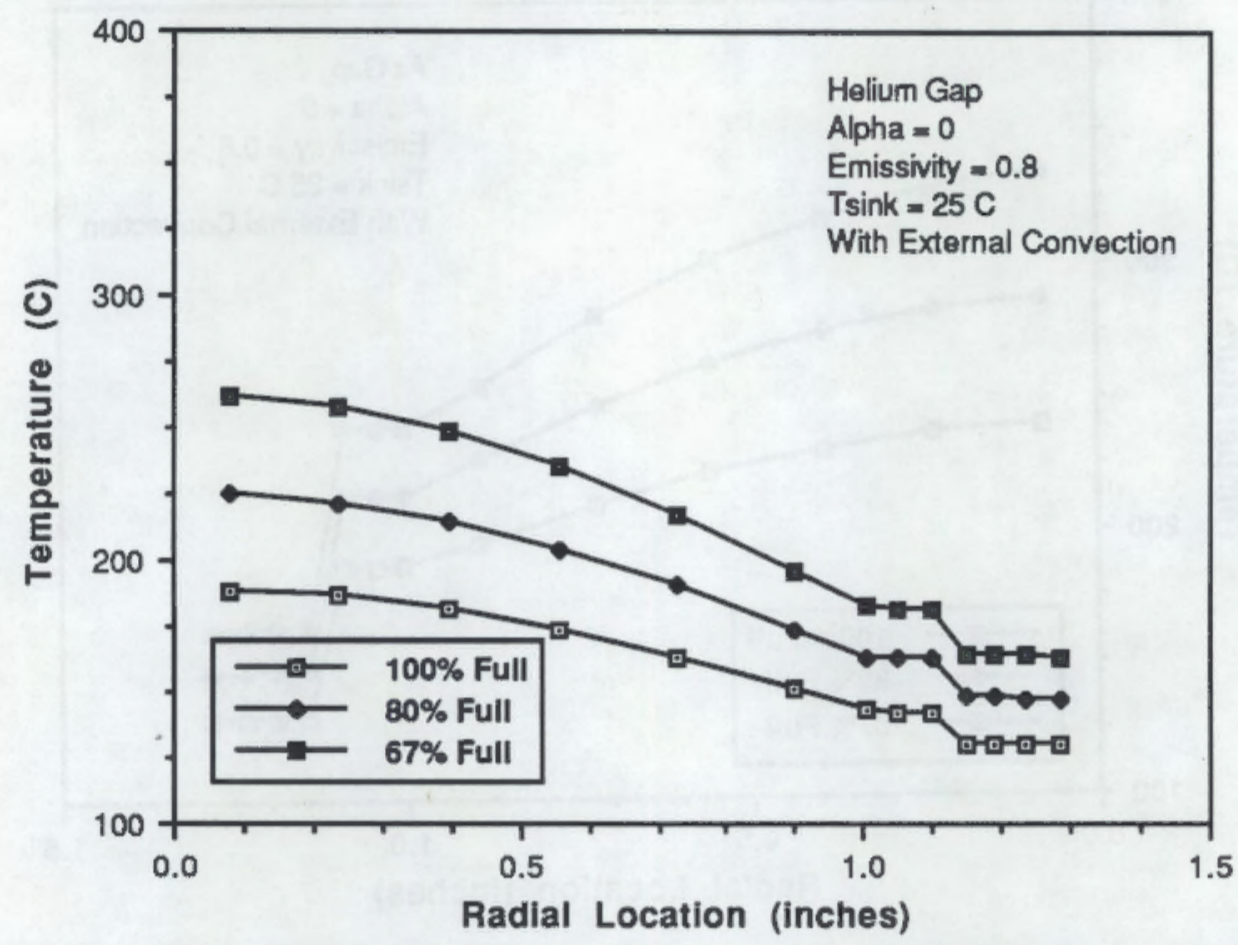

FIGURE 5.8. Radial Temperature Distributions with Helium in the Capsule Gap

as an infinitely long tube, the power per unit length is the important parameter. Therefore, the calculations for a $160-W$ capsule that is only $67 \%$ filled with $\mathrm{CsCl}$ would correspond to a completely filled capsule with a power output of $240 \mathrm{~W}$ (i.e., with the same power per unit length). However, the boundary condition calculation described earlier was performed based on $160-\mathrm{W}$ capsule power.

\subsubsection{Temperature Dependence On Heat Transfer Between Capsules}

To investigate the dependency of temperatures on heat transfer between capsules, several tests of the midplane model were run. Varying $\alpha_{\mathrm{ad}}$, as discussed above, allowed parameterization of the heating due to adjacent capsules. In addition, the effect of including (or excluding) convective heat transfer at the outer boundary was examined. The maximum temperature in a capsule, as a function of the adiabatic angle, is plotted in Figure 5.9. The base case maximum temperature increases from $240^{\circ} \mathrm{C}$ ( for $\alpha_{\mathrm{ad}}=0^{\circ}$ ) to $308^{\circ} \mathrm{C}$ when $\alpha_{a d}$ is increased to $45^{\circ}$. For a more realistic value of $\alpha_{a d}=15^{\circ}$, an increase of $15^{\circ} \mathrm{C}$ ( to $255^{\circ} \mathrm{C}$ ) in the maximum temperature is calculated. 


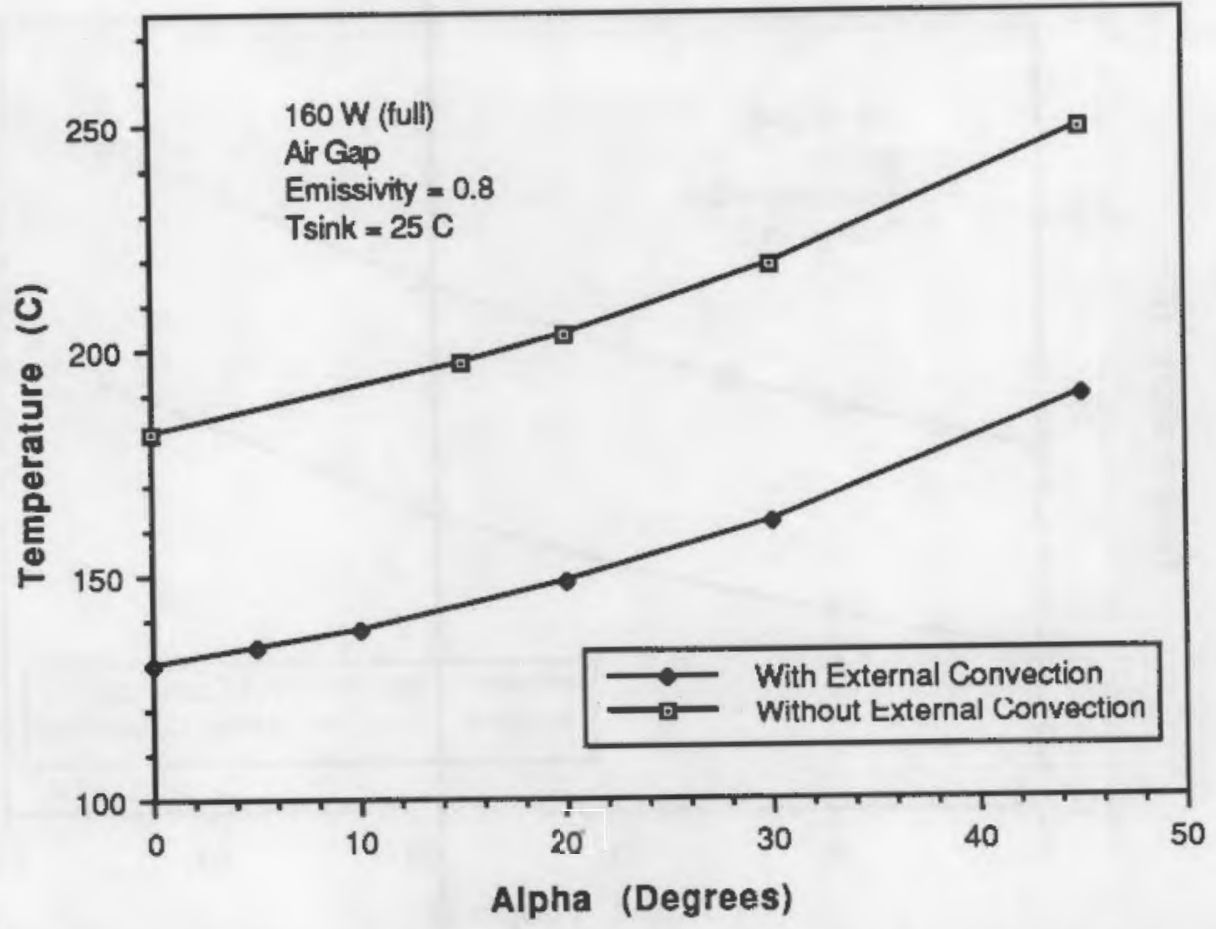

FIGURE 5.9. Maximum Temperature Dependence on the Adiabatic Angle

This figure also shows that the external convection provides a $50^{\circ} \mathrm{C}$ to $60^{\circ} \mathrm{C}$ reduction in the maximum temperature.

The surface temperature at $90^{\circ}$ (perpendicular to the array of cesium capsules) is plotted as a function of $\alpha_{a d}$ in Figure 5.10. As is shown in the figure, the surface temperature behaves very similarly to the maximum centerl ine temperature. This surface temperature increases from $130^{\circ} \mathrm{C}$ for the base case to $189^{\circ} \mathrm{C}$ when $\alpha_{a d}=45^{\circ}$. The external convective heat transfer provides a $50^{\circ} \mathrm{C}$ to $60^{\circ} \mathrm{C}$ reduction in the surface temperature.

Figure 5.11 presents the azimuthal temperature variation, as a function of $\alpha_{\text {ad }}$. Since $\alpha_{a d}=0^{\circ}$ ignores the direct heating due to neighboring capsules, the problem becomes independent of theta, and no azimuthal variation in surface temperature is possible. As $\alpha_{a d}$ increases, a fairly weak variation in surface temperature is observed, with a maximum of $18^{\circ} \mathrm{C}$ variation at $\alpha_{a d}=45^{\circ}$. The convective heat transfer can be seen to negligibly affect the surface temperature variation. 


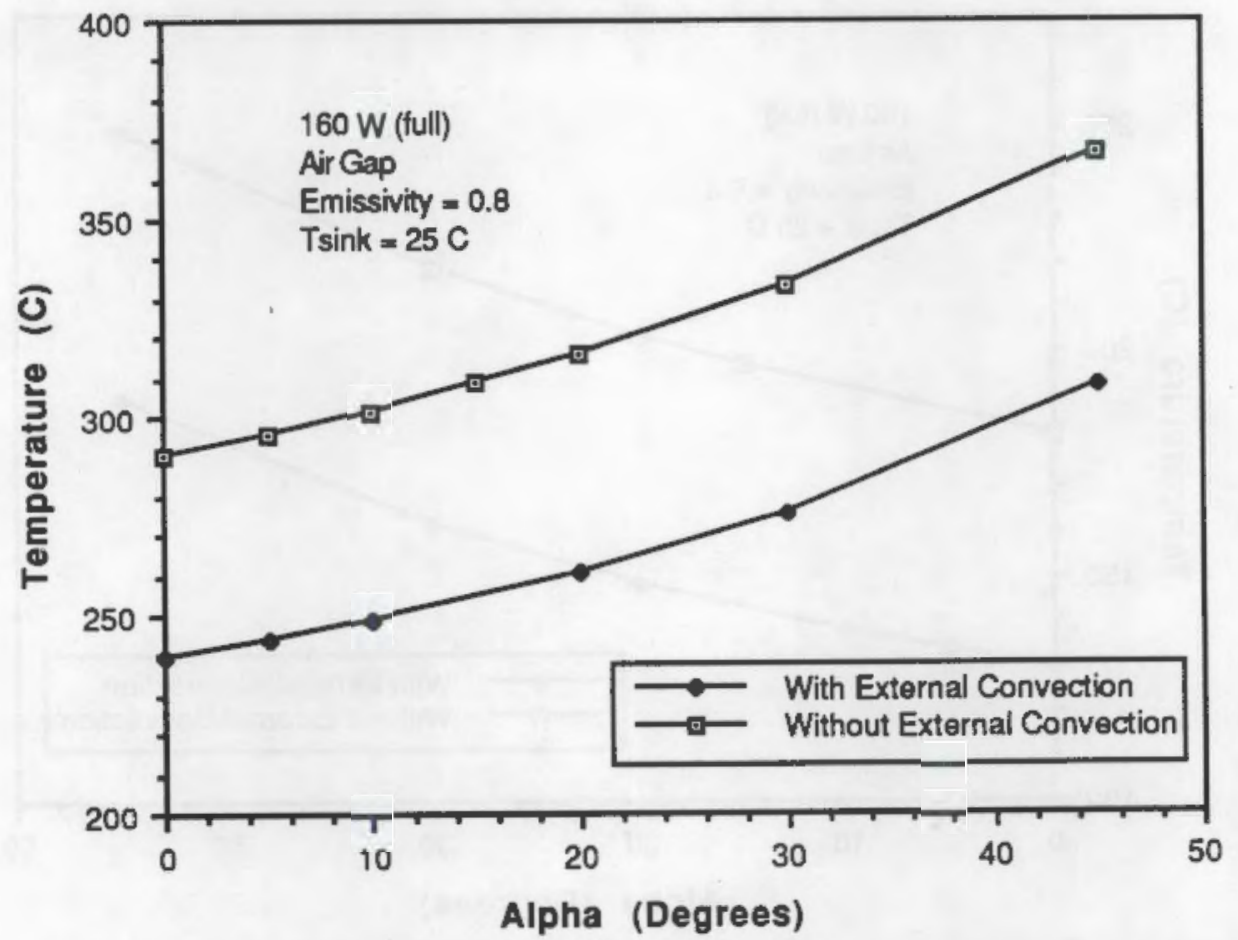

FIGURE 5.10. Surface Temperature Dependence on the Adiabatic Angle

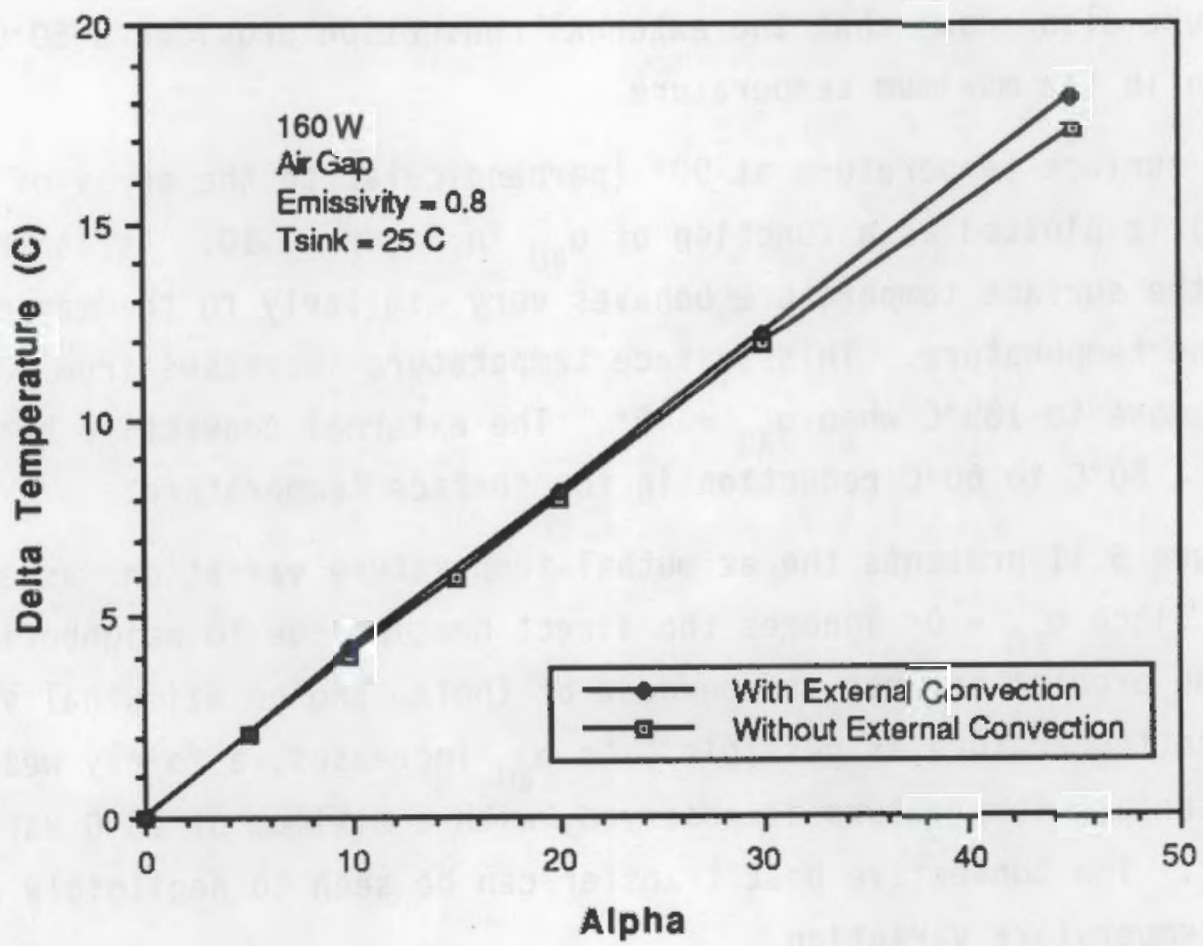

FIGURE 5.11. Surface Temperature Variation 
It is useful to note that interior to the capsule, there is very little azinuthal temperature variation. For example, at $\alpha_{\text {ad }}=45^{\circ}$, the azimuthal temperature difference in the interior stainless steel wall is only $2^{\circ} \mathrm{C}$. This occurs because the stainless steel thermal conductivity is rather large $\left(\mathrm{k} \approx 17 \mathrm{~W} / \mathrm{m}-{ }^{\circ} \mathrm{C}\right)$ relative to that of the $\mathrm{CsCl}$. Thus, azimuthal variations in external heat transfer are negated by angular conduction in the two layers of stainless steel.

\subsubsection{Effect of External Sink Temperature}

In the analysis of external thermal conditions, it is evident that convection and thermal radiation may see different temperatures. For example, in convection,

$$
q_{c}=h_{c}\left(T_{\text {surf }}-T_{\text {sink }}\right)
$$

the convection sink temperature is the temperature of the air layer between the wire mesh and the capsules. In thermal radiation,

$$
a_{r}=h_{r}\left(T_{\text {surf }}-T_{\text {sink }}\right)
$$

the radiation sink temperature may be the wire mesh temperature, the shroud temperature, or some other effective temperature if the shroud is not present. It is even possible that for a situation where two racks are visibly opposed, the sink temperature may be largely a function of capsule surface temperatures of the opposing rack. In any case, determining an exact sink temperature for the thermal radiation is very difficult.

To investigate this effect on external capsule heat transfer, the sink temperature for thermal radiation was varied. Results are presented in Figure 5.12 for the case of $Q_{\text {tot }}=160 \mathrm{~W}$ with $\epsilon=0.8, \alpha_{\text {ad }}=45^{\circ}$, and $T_{\text {sink }}$ for convection of $149^{\circ} \mathrm{C}$. Note that as the radiation sink temperature increases from 25 to $149^{\circ} \mathrm{C}$, the maximum center temperature adjusts upwards. For the latter, the maximum center temperature is near $382^{\circ} \mathrm{C}$. This is about $32^{\circ} \mathrm{C}$ higher than for the case of $\mathrm{T}_{\text {sink, } \mathrm{rad}}=25^{\circ} \mathrm{C}$. The implication here is that if the sink temperature for thermal radiation is high, such as for the 


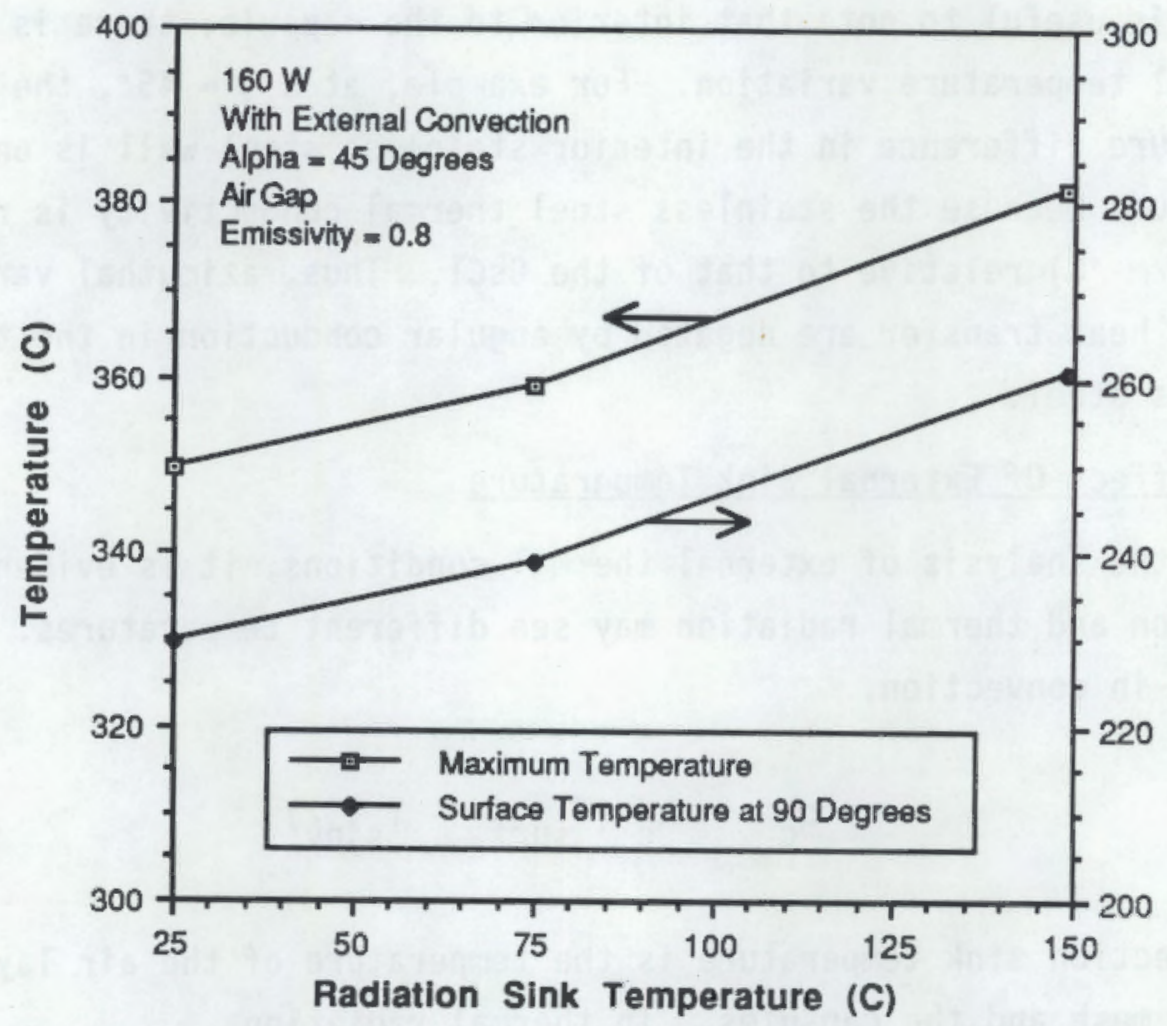

FIGURE 5.12. Effect of Thermal Radiation Sink Temperature

side where the capsules "see" surfaces of capsules in an opposing rack, center maximum temperature could become rather warm.

\subsubsection{Effect of Stainless Steel Emissivity}

Figure 5.13 presents the maximum (centerline) temperature in the $\mathrm{CsC} 1$ as a function of stainless steel emissivity. Values range from $\epsilon=0.4$ to 0.8 . Note that the maximum temperature, $T_{m}$, is strongly dependent on this value. At $\epsilon=0.8$ the centerline temperature is $308^{\circ} \mathrm{C}$ and goes up to $367^{\circ} \mathrm{C}$ for $\epsilon=0.4$. These results are for $\alpha_{\mathrm{ad}}=45^{\circ}$.

\subsubsection{Effect of Gamma Heating}

The $\mathrm{CsCl}$ salt is both a gamma emitter and a beta emitter. It is not a primary objective of this work to perform an exhaustive analysis of the nuclear radiation heating effects of the gamma and beta rays. However, it is useful to investigate the power distribution effects caused by gamma heating. This is done in an approximate way to estimate: a) the power distribution in 


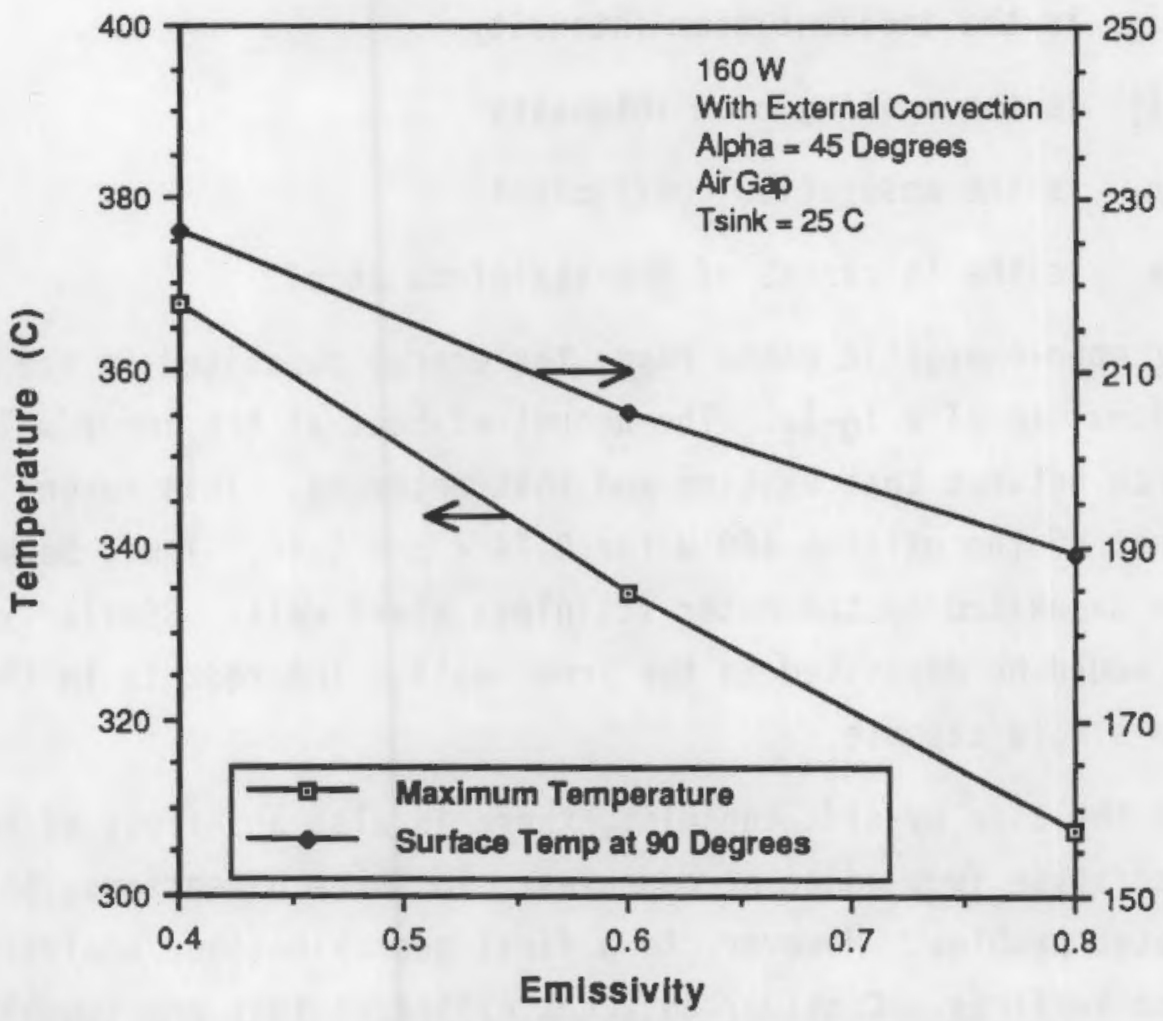

FIGURE 5.13. Effect of Emissivity on Temperature

the $[\mathrm{sCl}$ versus gamma heating in the stainless steel, and b) the effect of gamma heating because of the adjacent capsules.

First, consider one capsule. If it is assumed that the total thermal power at the outer surface of a single capsule is $160 \mathrm{~W}$, then, working inward, one can estimate the fraction of this power that is emanating in the $\mathrm{CsCl}$ compared to the stainless steel. From El-Wakil (1962), the absorption coefficient for gamma rays in stainless steel ranges from 0.46 to $0.24 \mathrm{~cm}^{-1}$ for 1 to $6 \mathrm{Mev}$ gamma rays, respectively. Assuming a slab model, the attenuation in intensity of the flux beam is

$$
I_{1}=I_{0} e^{-\mu x}
$$


where $I_{0}$ is the incident beam intensity

$I_{1}$ is the exiting beam intensity

$\mu$ is the absorption coefficient

$x$ is the thickness of the stainless steel.

For mono-energetic gamma rays, the energy deposited in the material is proportional to $\Delta I=I_{0}-I_{1}$. The amount of heat at the inner wall is then the difference between that exiting and that entering. This ranges between 8 and 15 percent of the exiting $160 \mathrm{~W}$ for $0.24<\mu<0.46$. Thus, between 13 and $24 W$ are deposited in the outer stainless steel wall. Similarly, between 12 to $22 \mathrm{~W}$ would be deposited in the inner wal1. The rest is in the CsC1. This is for a single capsule.

For the side-by-side capsules, there is also an effect of heating by gamma radiation from adjacent capsules. In three dimensions, this is a very complicated problem. However, to a first approximation, analyzing a planar situation suffices. Consider adjacent cylinders that are touching. Then a beam of radiation leaving one cylinder (assuming no scattering) will "see" adjacent cylinders according to a "view factor, "much the same as in thermal radiation. Such a factor for infinitely long cylinders of equal radi $i$ (Siegel and Howell 1981) is

$$
F_{1-2}=\frac{1}{\pi}\left(\sqrt{x^{2}-1}+\sin ^{-1}\left(\frac{1}{x}\right)-x\right)
$$

where

$$
x=1+\frac{s}{2 r}
$$

and $\quad s$ is the separation distance between cylinders

$$
r \text { is the cylinder radius. }
$$

In the present case, with no space between adjacent cylinders, the separation distance becomes $2 n r$ where $n$ is the number of cylinders (diameters) between the two of interest. Table 5.2 presents this view factor. Thus, for example, of gamma rays bearing a cylinder surface at any angle and 


\section{TABLE 5.2. Radiation View Factors}

\begin{tabular}{|c|c|c|}
\hline $\begin{array}{c}\text { Separation } \\
\text { Diameters } \\
\mathrm{n}\end{array}$ & $\begin{array}{l}\text { View } \\
\text { Factor } \\
\text { Fl-2 }\end{array}$ & $\begin{array}{c}\text { Incidence } \\
\text { Factor } \\
f_{l}=2 \\
\end{array}$ \\
\hline 0 & 0.180 & 0.144 \\
\hline 1 & 0.081 & 0.078 \\
\hline 2 & 0.054 & 0.053 \\
\hline 3 & 0.040 & 0.039 \\
\hline 4 & 0.032 & 0.032 \\
\hline 5 & 0.026 & 0.026 \\
\hline
\end{tabular}

traveling a straight path, only 3.2 percent of them would "see" a cylinder four diameters away. On the other hand, if gamma rays were assumed to be emitted normal to the emitting cylinder surface, based on geometry, incidence factors would be slightly less until the separation became greater than three diameters.

Using these factors, an estimate of the gamma heating for radiation from other cylinders in a line can be obtained. For two adjacent cylinders, the intensity degradation would be

$$
\Delta I_{0-1}=I_{0} F_{0,1}\left(1-e^{-\mu_{1} \Delta x_{1}}\right)
$$

where

$I_{0}$ is the intensity leaving cylinder 0

$F_{0,1}$ is the view factor between cylinders 0 and 1

$\mu_{1} \quad$ is an absorption coefficient of cylinder 1

$\Delta x_{1} \quad$ is an effective absorption distance.

For cylinders separated by other cylinders of equal diameter, the expression is:

$$
\Delta I_{0-n}=I_{0} e^{-\sum \sum_{i=1}^{n-1} \mu_{i} \Delta x_{i}}\left(F_{0, n-1}-F_{0, n} e^{-\mu_{n} \Delta x} n\right)
$$

To a first approximation, $\mu=0.25$ for stainless steel can be used. 
To a first approximation, $\mu=0.25$ for stainless steel can be used. (Because $\mu / \sigma$, the mass absorption coefficient, is approximately constant, $\mu$ for $\mathrm{CsCl}$ is about a factor or 2 less than $\mu$ for stainless steel.) For an effective distance, $\Delta x_{1}=\sqrt{2} \mathrm{D} / 2$ can be used. With these assumptions, the fraction of gamma heating for cylinders separated by $n$ diameters can be determined. These are listed in Table 5.3.

Thus, heating by gamma radiation from capsules separated by more than one diameter is quite negligible. Assuming that heating is directly proportional to intensity decrement, $\Delta \mathrm{I}_{0-n}$, then approximately 12 percent of the total equivalent energy leaving a capsule by gamma radiation is estimated to be deposited in an adjacent capsule. Approximately 4.7 percent would result from the next furthest capsule for a total of 16.7 percent gamma heating because of the adjacent capsules. (This is the percentage of gamma-ray energy leaving a capsule, not deposited.) Thus if, for example, the incipient thermal energy were $160 \mathrm{~W}$ in a capsule, because of self-heating, and $240 \mathrm{~W}$ were the total equivalent energy of all gamma radiation in a capsule, then the amount of gamma heating that could occur in the capsule due to adjacent capsules on one side would be $0.167(240-160)=13.4 \mathrm{~W}$. Thus, in an array of six capsules, the central ones could experience as much as twice this amount, or $26.8 \mathrm{~W}$ for a total of $186.8 \mathrm{~W}$.

Figure 5.14 presents a comparison of the radial temperature distribution for a single capsule with a power of $160 \mathrm{~W}$ and a capsule with $186.8 \mathrm{~W}$ resulting from adjacent capsule gamma heating. For both capsules the base case parameters are used for the stainless steel emissivity, gap gas, sink

TABLE 5.3. Gamma-Heating Factors

\begin{tabular}{|c|c|}
\hline $\begin{array}{c}\text { Separation } \\
\text { Diameters } \\
n\end{array}$ & $\begin{array}{l}\text { Intensity } \\
\text { Decrement } \\
\Delta \mathrm{I}_{0-n}\end{array}$ \\
\hline 0 & $=0.12 \mathrm{I}_{0}$ \\
\hline 1 & $0.047 \mathrm{I}_{0}$ \\
\hline 2 & $0.002 \mathrm{I}_{0}$ \\
\hline
\end{tabular}




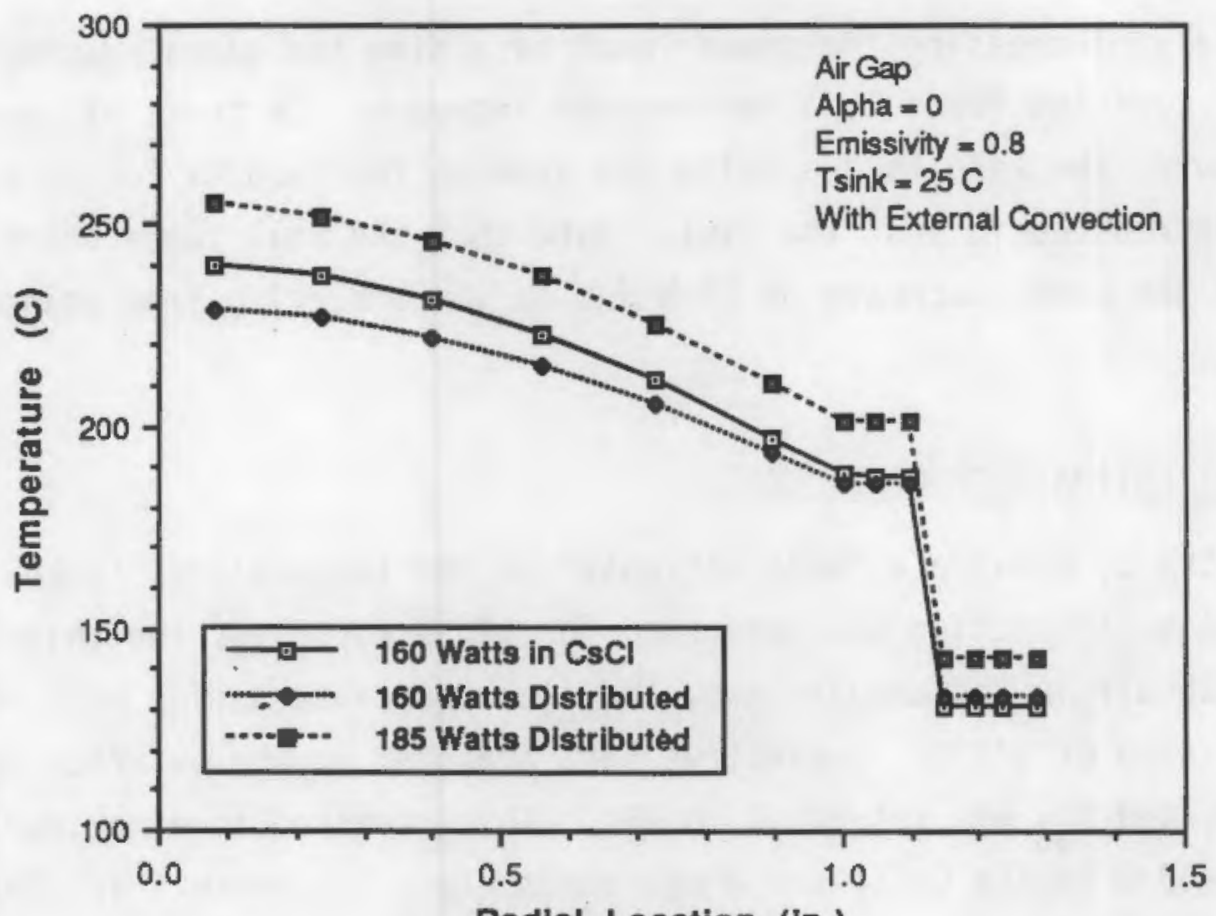

Radial Location (in.)

FIGURE 5.14. Radial Temperature Profiles for Distributed Power Calculations

temperatures, and convective heat transfer. In both cases, energy is deposited as if gamma heating occurred in the stainless steel. Table $\mathbf{5 . 4}$ presents the power deposition by material.

For a constant total thermal power leaving the outside surface, distributing that power, such as caused by gamma heating in the stainless steel, results in a decrease in maximum (centerline) temperature. This decrease is about $12^{\circ} \mathrm{C}$ for the $160-W$ case with air in the gas gap.

TABLE 5.4. Power Deposition for Results in Figure 5.13

\begin{tabular}{|c|c|c|c|}
\hline $\begin{array}{l}\text { Total } \\
\text { Power } \\
\text { (W) }\end{array}$ & $\begin{array}{l}\text { Power in } \\
\text { CsCl } \\
\text { (W) }\end{array}$ & $\begin{array}{c}\text { Power in } \\
\text { Inner Stainless } \\
\text { Steel Wall } \\
\text { (W) }\end{array}$ & $\begin{array}{l}\text { Power in } \\
\text { Outer Stainless } \\
\text { Steel Wall } \\
\text { (W) }\end{array}$ \\
\hline 160 & 135 & 12 & 13 \\
\hline 186.8 & 157.6 & 14.0 & 15.2 \\
\hline 160 & 160 & 0 & 0 \\
\hline
\end{tabular}


Alternately, increasing the power level by adding the gamma heating effect of adjacent capsules leads to a temperature increase. In terms of the excess temperature, the results are quite the same as the results for an equivalent power distributed in just the $\mathrm{CsCl}$. Note that the wall temperature went up $12^{\circ} \mathrm{C}$ for the power increase of $25 \mathrm{~W}$ due to gamma heating from adjacent capsules.

\subsection{BEST ESTIMATE OF WORST CASE}

To try to provide a "best estimate" of the temperatures in the hottest capsules, a calculation was performed for $160 \mathrm{~W}$ capsules, two-thirds full of $\mathrm{CsCl}$, with air in the annular gap, and sink temperatures for both convection and radiation of $149^{\circ} \mathrm{C}$. Convective heat transfer on the exterior surface was included, and $\alpha_{\text {ad }}$ was set equal to $23^{\circ}$. This resulted in a maximum temperature of $468^{\circ} \mathrm{C}$ in the $\mathrm{CsCl}$, and a maximum surface temperature of $289^{\circ} \mathrm{C}$. The temperature profile in the center plane perpendicular to the array of capsules is shown in Figure 5.15 .

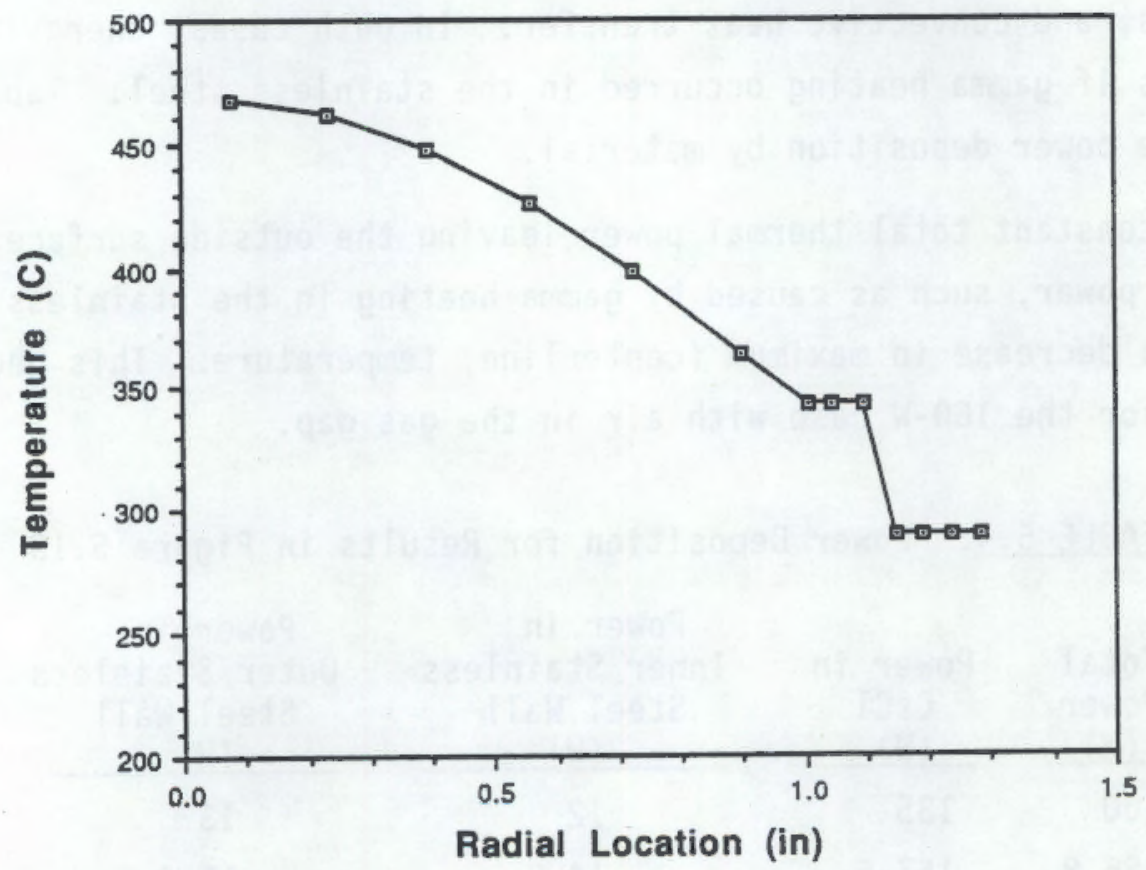

FIGURE 5.15. Radial Temperature Distribution for "Best Estimate of Worst Case" Calculation 


\section{REFERENCES}

E1-Waki1, M. M. 1962. Nuclear Power Engineering. McGraw Hi11, New York. Holman, J. P. 1963. Heat Transfer. McGraw Hill. New York.

Knecht, W. L. 1988. "Engineering Notebook for Thermal Analys is of Cesium Capsules." SD-WM-DA-109. Westinghouse Hanford Company. Richland, WA.

Siegel, R. and J. R. Howe11. 1981. Thermal Radiation Heat Transfer. McGraw Hill, New York.

Sparrow, E. M., et al. 1961. "Heat Transfer to Longitudinal Laminar Flow Between Cyl inders." Journal of Heat Transfer.

Tingey, G. L., W. J. Gray, R. J. Shippel1, and Y. B. Katayama. 1985. "WESF Cesium Capsule Behavior at High Temperature or During Thermal Cycling." PNL5517. Pacific Northwest Laboratory. Richland, Washington.

Trent, D. S. and L. L. Eyler. 1989. "TEMPEST A Three-Dimensional TimeDependent Program for Hydrothermal Analysis." PNL-4348, Vol I, Rev. 2. Pacific Northwest Laboratory, Richland, Washington.

Trent, D. S. and L. L. Eyler. 1988. "ARIEL: A Computer Program for Hydrodynamic Simulation in Curvilinear Coordinates." Pacific Northwest Laboratory, Richland, Washington. 

APPENDIX A

MATERIAL PROPERTIES 
APPENDIX A

\section{MATERIAL PROPERTIES}

Thermal conductivity of $\mathrm{CsCl}$ was interpolated from Knecht (1988); density was from Tingey (1988). The tabulated values used in this analysis are:

\begin{tabular}{ccc}
$I\left({ }^{\circ} \mathrm{C}\right)$ & $\begin{array}{c}\text { Thermal Conductivity } \\
k\left(W / \mathrm{m}-{ }^{\circ} \mathrm{C}\right)\end{array}$ & $\begin{array}{c}\text { Density } \\
\frac{\sigma\left(\mathrm{kgm} / \mathrm{m}^{3}\right)}{}\end{array}$ \\
\cline { 2 - 3 } 10 & 0.86 & 4061 \\
35 & 0.81 & 4033 \\
60 & 0.76 & 4013 \\
\hline 85 & 0.71 & 3996 \\
110 & 0.67 & 3977 \\
135 & 0.63 & 3965 \\
\hline 160 & 0.58 & 3953 \\
185 & 0.55 & 3937 \\
210 & 0.51 & 3925 \\
\hline 235 & 0.48 & 3909 \\
260 & 0.45 & 3900 \\
285 & 0.42 & 3882 \\
\hline 310 & 0.40 & 3857 \\
335 & 0.38 & 3831 \\
360 & 0.35 & 3804 \\
\hline 385 & 0.33 & 3779 \\
410 & 0.31 & 3753 \\
& &
\end{tabular}

A.1 
The specific heat was assumed constant at $311.1 \mathrm{~J} / \mathrm{kg}-{ }^{\circ} \mathrm{C}$.

Stainless steel properties were from the TEMPEST library. (Data was originally obtained from the Reactor Materials Handbook.) ${ }^{(a)}$ Thermal conductivity at $100^{\circ} \mathrm{C}$ was $17.1 \mathrm{~W} / \mathrm{m}-{ }^{\circ} \mathrm{C}$. Density was $8000 \mathrm{kgm} / \mathrm{m}^{3}$. Specific heat was $460 \mathrm{~J} / \mathrm{kgm}^{\circ} \mathrm{C}$.

Values of density and specific heat are inconsequential to the present analysis because only steady-state results were computed.

(a) Westinghouse Hanford Company proprietary report. 
PNL-7196

UC-721

\section{DISTRIBUTION}

No. of

Copies

OFFSITE

2 DOE/Office of Scientific and Technical Information

ONSITE

DOE Richland Operations office

E. C. Norman

23 Pacific Northwest Laboratory

R. E. Dodge, K5-02 (10)
No. of

Copies

B. M. Johnson, K5-02

P. S. Lowery, K5-21

E. W. Pearson, K5-02

G. J. Posakony, K2-28

C. W. Stewart, K5-02

D. S. Trent, K1-82

Publishing Coordination

Technical Report Files (5)

9 Westinghouse Hanford Company

H. R. Gardner, K5-52 (6)

W. L. Knecht, HO-33 (2)

K. V. Scott, K5-52 
